\title{
Sex and status in a cooperative breeding fish: behavior and androgens
}

\author{
Julie K. Desjardins $\cdot$ Kelly A. Stiver • \\ John L. Fitzpatrick • Nicole Milligan • \\ Glen J. Van Der Kraak • Sigal Balshine
}

Received: 15 November 2006 /Revised: 16 May 2007 / Accepted: 4 September 2007 / Published online: 3 October 2007

(C) Springer-Verlag 2007

\begin{abstract}
Among taxonomically widespread cooperatively breeding vertebrates, those with non-breeding helpers-atthe-nest provide an excellent opportunity to understand the proximate mechanisms underlying care and allocare. In this study, we examined androgen levels in relation to care behavior in a cooperatively breeding cichlid fish, NeOlamprologus pulcher, from Lake Tanganyika. We concentrated on androgens, as these hormones have been linked to the defense behavior, and the defense of young is a common form of parental care in fishes. $N$. pulcher dominant female breeders performed the most care and also displayed the highest levels of plasma testosterone (T) compared with other individuals within the social group. We also found that dominant male breeders provided a similar amount of care as did the subordinate helpers, but breeding males had the highest levels of 11-ketotestosterone (11KT), an important androgen in fish. Breeders had
\end{abstract}

Communicated by K. Lindström.

J. K. Desjardins · K. A. Stiver · N. Milligan · S. Balshine Animal Behaviour Group, Department of Psychology,

Neuroscience and Behaviour, McMaster University,

Hamilton, ON, Canada L8S 4K1

J. L. Fitzpatrick

Department of Biology, McMaster University,

Hamilton, ON, Canada L8S 4K1

G. J. Van Der Kraak

Department of Integrative Biology, University of Guelph,

Guelph, ON, Canada N1G 2W1

J. K. Desjardins $(\square)$

Department of Biological Sciences, Stanford University,

371 Serra St.,

Stanford, CA 94305, USA

e-mail: desjarjk@stanford.edu higher levels of both androgens ( $T$ and 11KT) compared to helpers. There was a weak but significant positive correlation between $\mathrm{T}$ levels and the frequency of care regardless of sex and status. Our results suggest that androgens may promote defense of young and are in contrast to the commonly reported trade-off between androgen and parental care.

Keywords Parental behavior Cooperation . Testosterone $\cdot 11$-Ketotestosterone $\cdot$ Cichlids . Proximate factors

\section{Introduction}

Cooperative breeding has been demonstrated in 120 species of mammals (Solomon and French 1997), 300 species of birds (Schoech et al. 2004), and eight species of fishes (Taborsky 1984). In these breeding systems, non-parental individuals called helpers contribute to the care of young, performing behaviors collectively referred to as "allocare". The expression of care and allocare is thought to be regulated by hormones. To date, most of the research on hormones in relation to care behaviors has concentrated on two hormones, prolactin (PRL) and testosterone (T; Mays et al. 1991; Schoech et al. 1991; Khan et al. 2001). This previous research has mainly been conducted on birds and mammals (Ziegler 2000); our study expands this line of investigation by examining the relationship between hormones and care as well as allocare in fishes.

Testosterone (T) is a steroid hormone, secreted primarily by the gonads, that is often linked to aggression, reproduction, and territory defense. A number of authors have argued that $\mathrm{T}$ interferes with the expression of parental care 
(Hegner and Wingfield 1987; Saino and Møller 1995; Ketterson et al. 1996). In birds and mammals, T levels are highest when males are nest building and courting, but dramatically decrease when males are providing care to young (birds: Wingfield et al. 1990; Peters et al. 2001; Foerster et al. 2002; Goymann et al. 2004; mammals: Ziegler 2000; Carlson et al. 2004; Young et al. 2005). In fish, the relationship between $\mathrm{T}$ and care is more ambiguous. Male sticklebacks (Gasterosteus aculeatus) showed dramatic increases in circulating androgens at the onset of spawning and nest building with subsequent decreases during paternal care (Páll et al. 2002). Treatments with exogenous androgens (11-ketotestosterone, a primary fish androgen) increased courtship behavior and reduced fanning rates compared to controls (Páll et al. 2002). However, Sikkel (1993) found no difference in either of these androgens ( $T$ or $11 \mathrm{KT}$ ) in mating and caring garibaldi fish (Hypsypops rubicundus). In addition, in the midshipman fish (Porichthys notatus), no differences in androgen levels were found between males with and males without eggs (Knapp et al. 1999). Recent research has shown that in fishes, parental behavior may be enhanced (rather than inhibited) by androgens (Ros et al. 2004; Magee et al. 2006; Rodgers et al. 2006).

While the study of $\mathrm{T}$ profiles and the relationship between testosterone and behavior has been primarily studied in males, the presence and action of testosterone is not exclusively confined to males. Across most vertebrate taxa, adults of both sexes naturally produce $\mathrm{T}$ (Nelson 2000), and $\mathrm{T}$ in females has been implicated in many different physiological and behavioral functions (Staub and De Beer 1997; Ketterson et al. 2005; Møller et al. 2005). In the female spotted hyenas (Crocuta crocuta), $\mathrm{T}$ mediates the expression of female dominance behavior and male-like female physiology (Lindeque and Skinner 1982). It has also been shown that $\mathrm{T}$ in females varies across the breeding season (Ketterson et al. 2005) and that females of many species respond behaviorally to exogenous $\mathrm{T}$ (Ketterson et al. 2005). For example, in female dark-eyed juncos (Junco hyemalis), experimental increased $\mathrm{T}$ levels resulted in increased aggression between same-sex individuals (Zysling et al. 2006). In female fish, the relationship between $T$ and behavior has not previously been explored.

Testosterone profiles have been examined in mammalian and avian cooperative breeding species in which subordinates help raise the young of other individuals in a social group. Among cooperative breeders, the dynamics of $\mathrm{T}$ expression have been shown to be equivalent between breeders and (Ziegler 2000). Like breeders, helpers' androgen levels tend to be much higher earlier in the reproductive cycle before the young emerge compared to levels when there are young in the nest (Wingfield et al. 1990; Mays et al. 1991; Vleck and Brown 1999). In some cooperative species, absolute levels of $\mathrm{T}$ are similar between male helpers and male breeders, while in other species, male breeders have been shown to have higher levels than male helpers (Schoech et al. 1996; Vleck and Brown 1999; Khan et al. 2001). Two previous laboratory studies have examined androgens in a cooperatively breeding fish (Oliveira et al. 2003; Bender et al. 2006), and both have shown that absolute androgens levels were identical between dominant male breeders and subordinate male helpers, as has been shown in some of the bird and mammal research.

The vast majority of the previous research on cooperative breeding and androgens has compared male breeders to male helpers. In this study, we compared androgen profiles between breeders and helpers in both males and females of the cooperative breeding cichlid fish, Neolamprologus pulcher. This species is endemic to Lake Tanganyika and we conducted this study on wild fish. Specifically, the aims of our study were threefold: (1) to examine whether sex and social status (breeder, helper) are related to androgen levels, (2) to determine how sex and status are related to rates of care and other behaviors such as social interactions, and (3) to relate individual levels of care, especially defense, to circulating levels of androgens.

\section{Materials and methods}

Study species, field site, and behavioral measures

$N$. pulcher live in social groups consisting of a dominant breeding pair and 1-20 helpers (males and females) that assist in all aspects of care (Taborsky 1984). Care consists of territory/nest defense, territory/nest maintenance, and direct brood care (fanning and cleaning of the eggs and larvae). Allocare or helping has been shown to enhance the frequency and number of young produced as well as offspring survival within the group (Taborsky 1984; Balshine et al. 2001; Brouwer et al. 2005). In this species, breeders can spawn monthly throughout the year, and care occurs continuously because dispersal is rare and breeders continue to protect helpers well into adulthood (Taborsky 1985; Stiver et al. 2004).

Between January 29th and April 29th in 2004 and between February 2nd and April 28th 2005, social groups were studied using SCUBA in Kasakalawe Bay, Lake Tanganyika (Zambia). The groups were located at 8.5-12 m of depth, and each territory was marked with uniquely labeled rocks. Each group was monitored one to three times (for an average of $15 \mathrm{~min}$ ) to assess group size and composition; each individual was reliably identified by a combination of underwater size estimates and specific individual markings. Fish were individually marked by fin 
clipping and injecting of nontoxic acrylic paints into scale pockets (see Balshine-Earn et al. 1998 for details). Behavioral recordings never occurred before a minimum of 3 days had elapsed since capture and marking. Mean group size in this study was nine individuals, two breeders, and seven helpers $(N=10$, range 6-14).

Two focal watches (7-10 $\mathrm{min})$ were conducted on 172 male breeders, 138 female breeders, 93 male helpers, and 95 female helpers. One focal watch was conducted in the morning and the other was conducted in the afternoon to control for diurnal variation in behavior (Werner et al. 2003); the behaviors recorded (see below) were averaged across the two watches. Each focal watch was preceded by a 2-min habituation period. Studies using underwater video cameras have shown that $N$. pulcher behavior is not significantly altered by the presence of scuba diving observers (S. Balshine, personal observation). Within minutes of the divers' arrival, individuals will feed, socialize, and actively defend their territory.

All behaviors observed were recorded on polyvinyl chloride plates and later transcribed into data sets at the surface. Behaviors included feeding, territory defense (aggressive behaviors such as ramming, chasing, biting, mouth fighting, and defensive posturing towards heterospecifics), territory maintenance (digging and carrying of substrate), brood chamber visits (where the eggs are laid), and social behaviors (following, soft touching, parrell swimming, tail quivering, and submissive postures; see Buchner et al. 2004 for a recent ethogram of these behaviors). Territory defense was defined as any aggressive behavior oriented towards heterospecifics. We restricted our analysis to heterospecifics and excluded aggression towards non-group conspecifics to ensure we were measuring behavior that was consistent with protection of young, not the protection of the mating territory, the mate, or the breeding position. Behaviors were recorded on individual fish, and we also noted the target of the behaviors and whether the target individual was a heterospecific or a conspecific, what species it was, and or whether or not it was a group member.

To score care, we used a composite that was the sum of all behaviors thought to enhance offspring survival; this included defense against heterospecifics, territory maintenance, and visits to the brood chamber. Defense was defined as any aggressive behavior oriented towards hetrospecifics. We use visits to the brood chamber as a proxy for direct brood care, as in the field, it is impossible to observe caring acts such as fanning and cleaning that occur deep in the brood chamber. We also analyzed defense, maintenance, and brood chamber visits individually. Within-group aggression was defined as a sum of all aggressive behaviors displayed towards one's own group members. We also used a composite score for social behavior that was a sum of all within-group non-aggressive behaviors (see above). These composite or summed scores for care, social behavior withingroup aggression have been used previously with this species (Balshine et al. 2001; Stiver et al. 2004; Bergmüller et al. 2005; Stiver et al. 2005). For further details of the study site, field methods, and behavioral observations, see BalshineEarn et al. (1998), Balshine et al. (2001), Buchner et al. (2004), Stiver et al. (2004, 2006), Fitzpatrick et al. (2006), and Desjardins et al. (2007).

\section{Blood sampling}

Blood samples were collected from 101 male breeders, 79 female breeders, 94 male helpers, and 92 female helpers. To collect fish, we placed a tent net directly over the entire group after the completion of the behavioral observations. We then carefully injected a small volume $(3-7 \mathrm{ml})$ of quinaldine [2-methylquinoline; $\left.\mathrm{C}_{6} \mathrm{H}_{4} \mathrm{~N}: \mathrm{C}\left(\mathrm{CH}_{3}\right) \mathrm{CH}: \mathrm{CH}\right)$, an anesthetic] into the center of the territory while the net was in place and collected the temporarily sedated fish. Fish from each group were placed together in individually marked mesh holding cages $(20 \times 20 \times 20 \mathrm{~cm})$ to recover from sedation and were then slowly $(\sim 20 \mathrm{~min})$ brought to the surface (see Fitzpatrick et al. 2006). At the surface, individuals were easily identified by a combination of body size information and natural as well as artificial individual markings on each fish.

Once at the surface of the water, fish were anesthetized with a lethal dose of benzocaine (Ethyl p-Aminobenzoate, $1.0 \mu \mathrm{g} / \mathrm{ml})$. Fish were then sexed by examining the genitalia and measured for standard length to the nearest millimeter. Body mass was measured to the nearest $0.001 \mathrm{~g}$, and a blood sample was taken by caudal severance. Sex was confirmed by gonadal examination. Blood was collected in heparinized micro-capillary tubes, spun at 8000 RPM for $10 \mathrm{~min}$, and the separated plasma was removed and stored at $-10^{\circ} \mathrm{C}$ for analysis of testosterone $(T)$ and 11-ketotestosterone (11KT). There was an unavoidable time delay between the initial sedation of the animals and the collection of hormone samples, a common logistical constraint in many field studies. As a result, the levels of androgens measured are possibly and even likely lower than the absolute levels expected in non-stressed fish. However, all fish, regardless of sex and status were handled in a similar manner, and we restricted our analysis and discussion to the determination of relative differences in androgen levels rather than absolute amounts. The blood plasma samples were transported back to Canada at $-4^{\circ} \mathrm{C}$ for hormone assay. After the 2004 field season, the samples were delayed by about $24 \mathrm{~h}$ (at room temperature) en route to Canada. We included these samples in our analyses, as the steroid levels in the 2004 samples were comparable to the levels measured in the 2005 samples. 
Hormone assays

We extracted steroids from plasma by shaking the aliquots with $5 \mathrm{ml}$ of diethyl ether twice. After freezing the aqueous phase in an acetone and dry ice bath, the organic phase was decanted and dried. The dry extracts were resolubilized in assay buffer and frozen at $-20^{\circ} \mathrm{C}$. Extraction losses were independently monitored and recoveries after a double extraction procedure were $88 \pm 4 \%$ (Desjardins et al. 2006). We used radioimmunoassay to measure $T$ and $11 \mathrm{KT}$ following the techniques to measure steroids from plasma described by McMaster et al. (1995). The reported values are the average concentrations calculated from duplicate aliquots whose values fell within the 5-95\% binding limits of the appropriate standard curve following the linearization with a log-logit transformation. Intra-assay coefficients of variation ranged from 5.8 to $9.3 \%$ for $T$ and from 4.2 to $8.9 \%$ for $11 \mathrm{KT}$. Inter-assay coefficients of variation did not exceed $15 \%$ in assays for $\mathrm{T}$ or $11 \mathrm{KT}$. The assays for $T$ and $11 \mathrm{KT}$ were validated for this species before the experiment and have been reported in Desjardins et al. (2006).

\section{Statistical analysis}

Statistical analyses were performed using the software JMP 5.1.1 (version 5.1, SAS Institute 2004). Data were tested for normality, transformed when necessary, and analyzed with parametric tests. Two-tailed tests were used throughout. We had larger samples for behavior than for hormone levels, as not all the fish observed were physiologically sampled. Samples with too small a volume to yield a detectable level of hormone were deleted from the dataset. When the blood sample was large enough to reveal a hormone level but a non-detectable hormone level was still observed, we estimated the minimum detectable level from the standard curve for this individual to ensure that the means are not artificially inflated by missing data.

We attempted to measure both $11 \mathrm{KT}$ and $T$ in all animals; however, given the small plasma volumes collected, we were often restricted to only one of these androgens. The variation in sample size between the two androgens reflects the fact that the fish were often simply too small to recover sufficient blood for the analysis of two hormones. Hence, all individuals included in the analysis of $11 \mathrm{KT}$ are included in the analysis of $T$ and vice versa. In the analysis of the ratio of $11 \mathrm{KT} / T$, only individuals for which both $11 \mathrm{KT}$ and $T$ were detectable using RIA were included. To test for the effect of sex and breeder/helper status on hormone levels and on behaviors, we used two-way analyses of variance (ANOVAs) and Tukey-Kramer post hoc tests. In the event of a significant interaction term in the two-way ANOVAs, linear contrast analysis was performed to interpret main effects. To test for relationships between
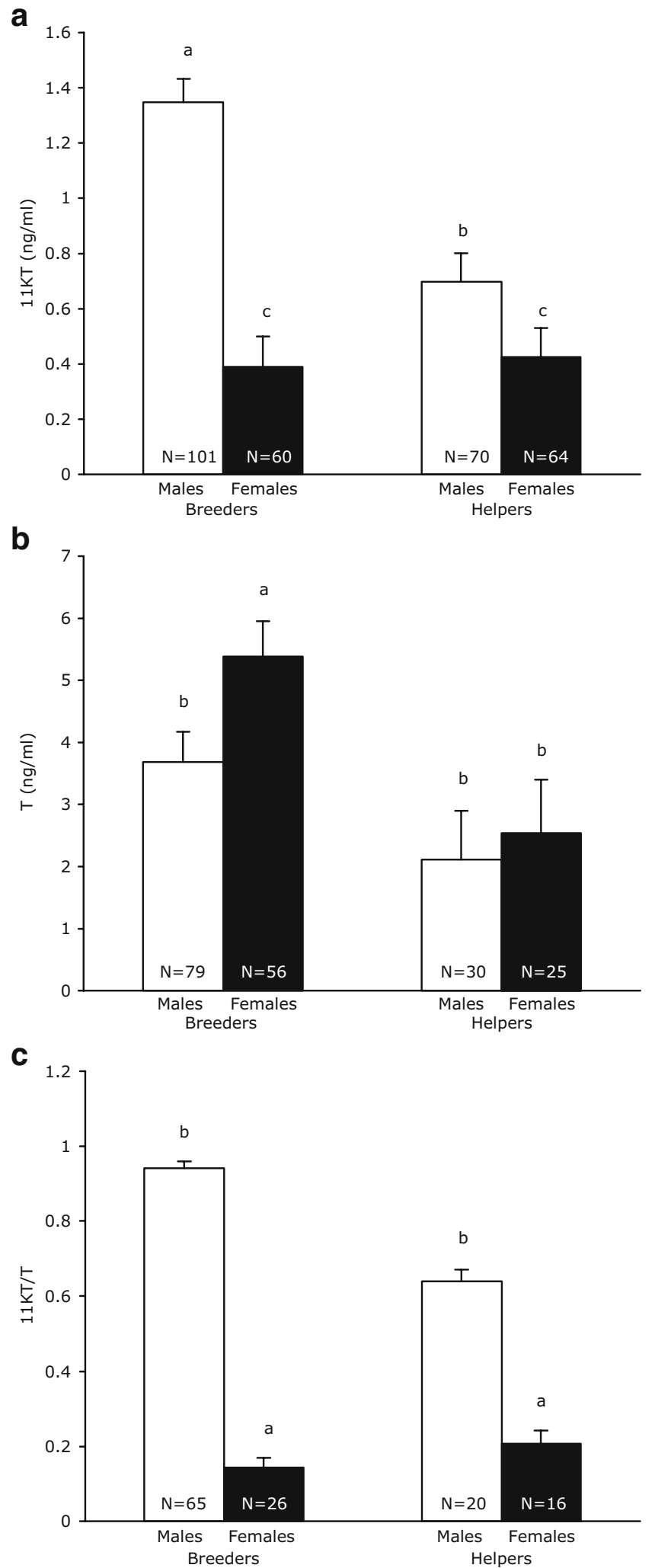

Fig. 1 The mean (+SE) level of plasma a $11 \mathrm{KT}$, b T, and $\mathbf{c} 11 \mathrm{KT} / \mathrm{T}$ as a function of sex and status. The different letters above the bars denote differences at $\alpha=0.05$ 
aggression and steroid hormones, Pearson's correlations and regression analyses were performed.

Ethical note

The fish were collected over two field seasons that spanned a 15-month period, and extreme care was taken not to collect fish from small subpopulations (less than ten groups). Neighboring groups were always left intact to minimize the impact of collection, and neighboring fish quickly recolonized emptied positions and territories, usually within 1-2 days. All research described conformed to the protocols approved by the Animal Research Ethics Board of McMaster University and the Canadian Council for Animal Care guidelines. Furthermore, this research was conducted with the permission and cooperation of the Zambian Department of Fisheries.

\section{Results}

Hormones, sex, and status

Overall, androgen levels were not related to group size (11KT: $F_{5,291}=1.168, p=0.33 ; T: F_{5,186}=1.822, p=0.11$ ), and this was also true when the relationship between androgens and group size was examined on all classes of classes of individuals separately (all $p>0.13$ ). Androgen levels were therefore treated as independent from group size. Males had higher levels of $11 \mathrm{KT}$ than females $\left(F_{1,291}=36.9\right.$, $p<0.001$, Fig. 1a), and breeders had higher levels of $11 \mathrm{KT}$ than helpers $\left(F_{1,291}=9.2, p=0.003\right)$. Male breeders had higher levels of $11 \mathrm{KT}$ than all other individuals (all $p<0.001$ ). Male helpers also had high levels of $11 \mathrm{KT}$, higher than both breeding females $(p<0.0001)$ and helper females $(p<0.0001)$. Female breeders and female helpers had similar levels of circulating $11 \mathrm{KT}$ ( $p=0.81)$.

Males and females had equal levels of T $\left(F_{1,186}=2.4, p=\right.$ 0.12 , Fig. 1b), but breeders had higher levels of $\mathrm{T}$ than helpers $\left(F_{1,186}=10.2, p=0.002\right)$. Female breeders had the highest levels of $\mathrm{T}$, and these were significantly higher than in all other classes of fish $\left(F_{1,186}=13.4, p<0.001\right)$. Male breeders, male helpers, and female helpers did not differ in their levels of $\mathrm{T}$ (all $p>0.23$ ). Some authors have suggested that the ratio between $11 \mathrm{KT}$ and $T$ is more informative than are absolute androgen levels because this ratio is a proxy for the physiological action of $\mathrm{T}$ (Oliveira 2006). We examined the $11 \mathrm{KT}$ to $T$ ratio in relation to sex and status in those individuals for which both of these androgens were available. Males (both breeders and helpers) had a higher $11 \mathrm{KT} / T$ ratio $\left(F_{1,123}=4.6, p=0.03\right.$, Fig. $\left.1 \mathrm{c}\right)$ than females. However, breeders and helpers had equal $11 \mathrm{KT} / T$ ratios $\left(F_{1,123}=0.2, p=0.68\right)$. a

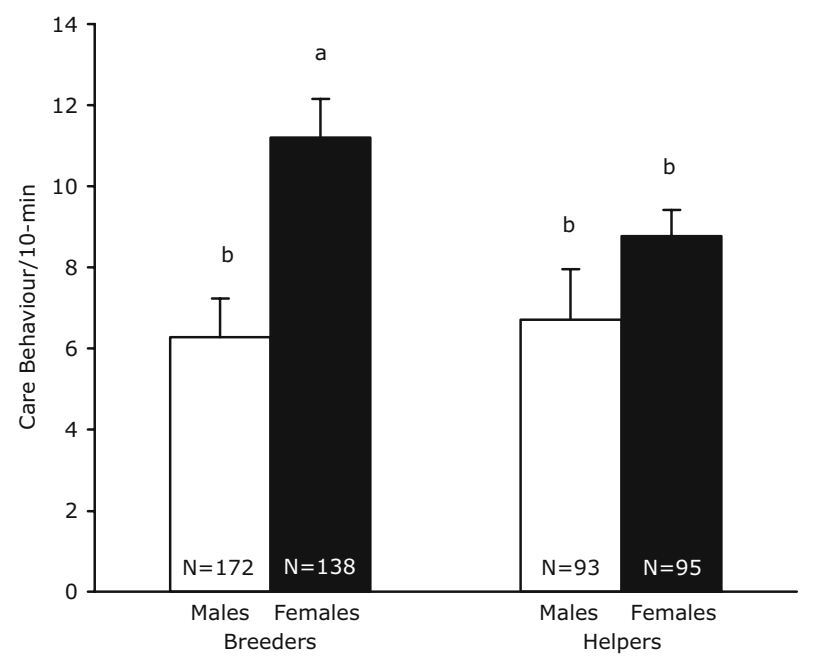

b

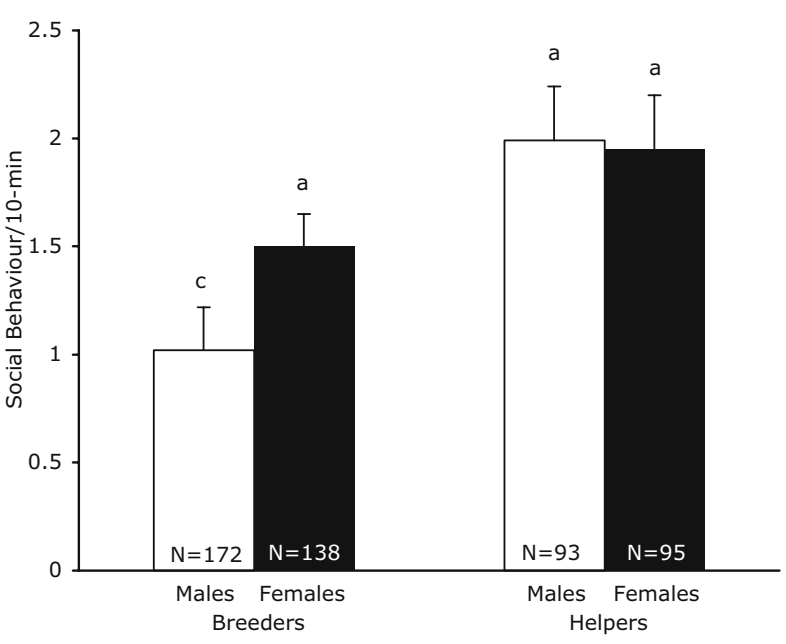

C

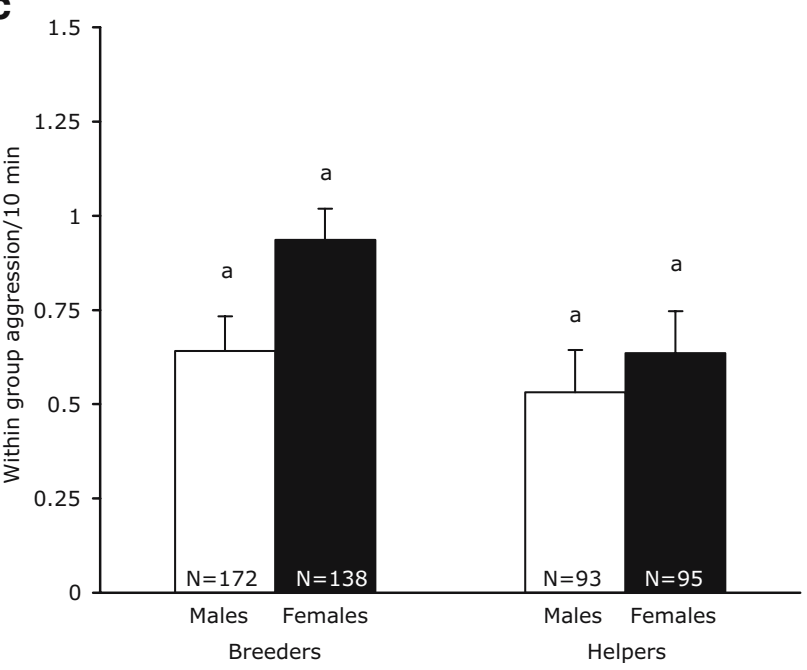

Fig. 2 The mean (+SE) rate of a care behaviors, (b) within-group non-aggressive social behaviors, and $\mathbf{c}$ within-group aggressive behaviors as a function of sex and status. Different letters denote significant differences at $\alpha=0.05$ 
Table 1 Results of two-way ANOVAs with the overall model results, the main effects (sex and status), and the interaction statistics for territory maintenance, brood chamber visits, and territory defense against heterospecifics

\begin{tabular}{lllll}
\hline Variable & Overall model & Main effect: sex & Main effect: status & Interaction \\
\hline Territory maintenance behaviors (\#/10-min) & $F_{3,493}=2.705$ & $F_{1,493}=4.590$ & $F_{1,493}=0.565$ & $F_{1,493}=1.165$ \\
& $p=0.04$ & $p=0.03$ & $p=0.45$ & $F_{1,493}=0.037$ \\
Brood chamber visits (\#/10-min) & $F_{3,493}=6.788$ & $F_{1,493}=11.084$ & $F_{1,493}=4.533$ \\
& $p=0.0002$ & $p=0.0009$ & $p=0.84$ & $p=0.03$ \\
Territory defense behaviors (\#/10-min) & $F_{3,493}=7.243$ & $F_{1,493}=2.679$ & $F_{1,493}=4.187$ & $p=0.04$ \\
& $p=0.0041$ & $p=0.10$ & $F_{1,493}=2.051$ \\
\end{tabular}

Care, allocare, and social behavior

Frequency of care depended on both the sex and the social status of the individual ( $\mathrm{sex} \times$ status: $F_{1,493}=3.3, p=0.02$, Fig. 2a). Female breeders provided more care than all other members of the group $\left(F_{1,493}=6.2, p=0.01\right)$, while male breeders and helpers (both males and females) performed similar levels of care $\left(F_{1,493}=1.3, p=0.26\right)$. Within each individual component of the care index (territory maintenance, brood chamber visits and territory defense), female breeders were also performing more of each of these behaviors (see Table 1).

Helpers performed more non-aggressive social behaviors than breeders $\left(F_{3,493}=13.1, p=0.003\right.$, Fig. $\left.2 b\right)$, but there were no sex differences in rates of social behaviors $\left(F_{3,493}=\right.$ $1.9, p=0.17)$. Male breeders participated in the fewest social behaviors compared to all other individuals $(p=0.01)$. Interestingly, there were no differences in within-group aggression displayed by males and females $\left(F_{3,493}=2.2, p=\right.$ 0.14 , Fig. 2 c) or by breeders and helpers $\left(F_{3,493}=2.4, p=0.12\right)$.

We examined 12 groups that had newly hatched young (fish 0.5 to $1.5 \mathrm{~cm}$ ) in the brood chamber/nest when the behavioral watches were conducted and compared these groups to 12 neighboring groups without young. We were unable to detect any differences between these groups with young $(N=12)$ and without young $(N=12)$ in the overall rates of territory maintenance activities (mean \pm SE: with young, $1.7 \pm 0.7$; without young, $0.8 \pm 0.7 ; F_{1,21}=2.507, p=$ 0.10 ), brood chamber visits (with young $=3.6 \pm 1.1$; without young $=3.9 \pm 1.0 ; F_{1,21}=2.488, p=0.12$ ), or territory defense against heterospecifics (with young $=0.7 \pm 1.1$; without young $=1.3 \pm 0.271 ; F_{1,21}=2.568, p=0.12$ ) Similarly, there were no detectable differences in $T$ or $11 \mathrm{KT}$ between individuals with young and without young (see Table 2).

Correlations between hormones and care

There was a weak but significant positive correlation between the frequency of care and testosterone when we examined all fish regardless of sex or status $\left(r^{2}=0.08, n=\right.$ 295, $p=0.005$, Table 3), and this pattern held when we controlled for the amount of time individuals spent on the territory $\left(r^{2}=0.08, n=295, p=0.007\right)$. We also examined the relationship between each of the composite components of care and $\mathrm{T}$ and found no significant relationships (Table 3). When we looked at all classes of individuals separately (Table 4), female breeders appeared to drive this significant positive relationship between care and $\mathrm{T}\left(r^{2}=0.13, n=60\right.$, $p=0.03$ ). Among female breeders, there were positive relationships between $\mathrm{T}$ and territory maintenance $\left(r^{2}=0.12\right.$,

Table 2 Comparisons of the androgens T, $11 \mathrm{KT}$, and $11 \mathrm{KT} / \mathrm{T}$ between individuals with and without fry

\begin{tabular}{|c|c|c|c|c|}
\hline \multirow[t]{2}{*}{ Individual } & \multirow[t]{2}{*}{ Hormone } & \multicolumn{2}{|c|}{ Mean \pm SE $(\mathrm{pg} / \mathrm{ml})$} & \multirow[t]{2}{*}{ Statistics } \\
\hline & & With fry & Without fry & \\
\hline \multirow[t]{3}{*}{ Male breeders } & $\mathrm{T}$ & $4.04 \pm 1.27$ & $3.19 \pm 1.95$ & $F_{1,16}=0.135, p=0.72$ \\
\hline & $11 \mathrm{KT}$ & $1.35 \pm 0.367$ & $0.90 \pm 0.41$ & $F_{1,16}=0.90, p=0.42$ \\
\hline & $11 \mathrm{KT} / \mathrm{T}$ & $0.46 \pm 0.20$ & $0.49 \pm 0.31$ & $F_{1,16}=0.008, p=0.93$ \\
\hline \multirow[t]{3}{*}{ Female breeders } & $\mathrm{T}$ & $6.24 \pm 1.38$ & $11.21 \pm 2.75$ & $F_{1,7}=1.61, p=0.20$ \\
\hline & $11 \mathrm{KT}$ & $0.33 \pm 0.15$ & $0.42 \pm 0.21$ & $F_{1,7}=0.124, p=0.73$ \\
\hline & $11 \mathrm{KT} / \mathrm{T}$ & $0.11 \pm 0.10$ & $0.043 \pm 0.21$ & $F_{1,7}=0.091, p=0.78$ \\
\hline \multirow[t]{3}{*}{ Male helpers } & $\mathrm{T}$ & $3.95 \pm 0.56$ & $3.05 \pm 0.63$ & $F_{1,10}=0.34, p=0.89$ \\
\hline & $11 \mathrm{KT}$ & $1.30 \pm 0.35$ & $0.65 \pm 0.33$ & $F_{1,10}=1.71, p=0.22$ \\
\hline & $11 \mathrm{KT} / \mathrm{T}$ & $0.33 \pm 0.12$ & $0.21 \pm 0.18$ & $F_{1,10}=0.54, p=0.69$ \\
\hline \multirow[t]{3}{*}{ Female helpers } & $\mathrm{T}$ & $5.91 \pm 4.49$ & $3.68 \pm 3.18$ & $F_{1,9}=0.16, p=0.75$ \\
\hline & $11 \mathrm{KT}$ & $0.63 \pm 0.19$ & $0.29 \pm 0.19$ & $F_{1,9}=1.632, p=0.21$ \\
\hline & $11 \mathrm{KT} / \mathrm{T}$ & $0.11 \pm 0.20$ & $0.077 \pm 0.12$ & $F_{1,9}=0.007, p=0.91$ \\
\hline
\end{tabular}


Table 3 Regression analysis of androgens (11KT, T, and $11 \mathrm{KT} / \mathrm{T})$ on composite care score

\begin{tabular}{llll}
\hline & $N$ & $R$ & $\beta$ \\
\hline Composite care score & & & $P$ \\
$11 \mathrm{KT}$ & 295 & -0.04 & -6.30 \\
$T$ & 190 & 0.16 & 171.34 \\
11KT:T & 127 & -0.008 & -0.0032 \\
Regression analysis & 190 & & 0.63 \\
$\quad$ Territory defense & 190 & 0.19 & 207.92 \\
Brood chamber visits & 190 & 0.025 & -63.12 \\
Territory maintenance & 0.14 & 375.80 \\
\hline
\end{tabular}

The regression analysis of $T$ on each of the components of the composite care score (territory defense against heterospecifics, visits to the brood chamber, and territory maintenance). All individuals (males, females, breeders, helpers) were combined for this analysis.

$N$ Sample size, $R$ Pearson's correlation, $\beta$ slope of the regression line

$n=60, p=0.05)$ as well as territory defense $\left(r^{2}=0.19, n=60\right.$, $p=0.01)$. No other significant relationships between androgens and care behavior were detected.

\section{Discussion}

We did not find evidence in support of testosterone having a negative impact on parental care in $N$. pulcher. The degree of parental care was in fact positively related, albeit weakly, to levels of T, suggesting a facilitating link between testosterone and parental care. In addition, no relationship was found between within-group aggressive behaviors and androgen levels. Our results are particularly important because until recently, the majority of experimental and observational data supported of a trade-off between levels of androgens and the degree of parental care (Wingfield et al. 1990; Vleck and Brown 1999; Clark and Galef 1999; Hirschenhauser et al. 2003; Peters 2002). High androgen levels were shown to enhance aggression in male-male competition, but were thought to be detrimental to parental care and rearing of young (Wingfield et al. 1990; Clark and Galef 1999; Hirschenhauser et al. 2003; Peters 2002 among others). However, the support for such a trade-off is now ambivalent with a number of recent studies, in addition to this one, finding no trade-off between androgens and parental care in birds, mammals and fishes (Creel et al. 1993; Van Duyse et al. 2000; Lynn et al. 2002, 2005; Ros et al. 2004; Magee et al. 2006; Rodgers et al. 2006). It appears that there are a number of ecological conditions under which T and parental care may not be linked (see Hau 2007 for a review). Our data suggest that high androgen levels are not necessarily deleterious to care but may actually promote effective parental care. Indeed, in a number of bird species with precocial young, males incubate and care for hatched young to a greater extent than females; yet, in these species, $\mathrm{T}$ levels are known to be higher in males than females, so, clearly, androgens do not always limit parental care (Oring et al. 1989; Gratto-Trevor et al. 1990).

$11 \mathrm{KT}$ was higher in male breeders than male helpers, while $T$ was higher in female breeders than female helpers. $N$. pulcher male breeders have much larger gonads than subordinate helpers and more competitive faster-swimming sperm (Fitzpatrick et al. 2006). A number of studies of cooperative breeders have shown a similar pattern; dominant male breeders have larger gonads and higher levels of $\mathrm{T}$ than male helpers (white browed sparrow weaver, Plocepasser mahali, Wingfield et al. 1991; bell miners Manorina melanophrys, Poiani and Fletcher 1994; Florida scrub-jays, Aphelocoma coerulescens, Schoech et al. 1996; superb fairy wrens, Malurus cyaneus, Peters et al. 2001). However, other studies of cooperative breeding species have reported similar levels of androgens between male breeders and male helpers (e.g., red cockaded woodpeckers, Picoides borealis, Khan et al. 2001; Mexican jays, Aphelocoma ultramarina, Vleck and Brown 1999). The different patterns

Table 4 Regression analysis of $T$ on composite care score (territory defense against heterospecifics, visits to the brood chamber, and territory maintenance)

\begin{tabular}{lllll}
\hline & $N$ & $\mathrm{R}$ & $\beta$ & $\mathrm{p}$ \\
\hline Male breeders & 79 & 0.04 & 44.69 & 0.77 \\
Female breeders & 56 & 0.25 & 138.60 & 0.015 \\
Male helpers & 30 & -0.02 & -135.29 & 0.41 \\
Female helpers & 25 & 0.04 & 89.75 & 0.55 \\
\hline
\end{tabular}

$N$ Sample size, $R$ Pearson's correlation, $\beta$ slope of the regression line 
observed within cooperative breeders appear not related to the degree of reproductive sharing within a social group because reproductive skew or sharing varies from high to low in both these groupings (Cockburn 1998; Creel 2001). This is the first study to examine hormone differences among females of different social states in fishes.

Mays et al. (1991) study on Harris hawks, Parabueus unicinctus, Asa et al. (1986) study on gray wolves (Canis lupus), and Poiani and Fletcher (1994) on bell miners are the only other studies, apart from this one, to have compared female breeders and helpers. Mays et al. (1991) showed, like we did in $N$. pulcher, that female breeders had higher levels of $\mathrm{T}$ than female helpers. Higher hormone levels were found in breeders vs helpers depending on sex and the androgen in question. Different androgens may control aggressive behavior in males and females $N$. pulcher, and indeed different hormones may modulate of parental care.

Given the small size of $N$. pulcher ( 3 to $6 \mathrm{~g}$ ), only a limited amount of plasma could be extracted, and our field study procedures were necessarily terminal. A non-invasive sampling method that facilitates repeated hormonal measures has been pioneered and used successfully with this species (see Oliveira et al. 2003; Bender et al. 2006). Unfortunately, this technique is currently only practical in a laboratory situation, as individuals need to be isolated in a known amount of water for $1 \mathrm{~h}$. Oliveira et al. (2003) and Bender et al. (2006) have used this technique to assess excreted androgens in a laboratory stock of $N$. pulcher. In contrast to our field results, the laboratory studies found no difference between male breeders and male helpers in excreted levels of $T$ and 11KT. However, previous studies did not include females and did not relate the frequency of care and other behavior to androgen levels. Additional work is now needed to resolve why excreted androgens and plasma androgens showed different patterns.

We have attempted to address whether androgens might be related to variation in parental care; however, there were some limitations to the level of analysis and the samples included in this study. We were able to show correlations between levels of $\mathrm{T}$ and care along a continuum from high to low. Over the course of two field seasons, we were able to closely monitor a large number of social groups; however, all of these groups were performing care for young and helpers to some extent. In $N$. pulcher, the defense of young and the territory by both breeders and helpers is continuous and occurs throughout an individual's lifetime. This limits our ability to detect differences between caring and non-caring individuals. When we compared between groups that had newly emerged young vs similar groups that did not, we were unable to detect any differences in $T, 11 \mathrm{KT}$, care, or territory defense. Future work in $N$. pulcher should address whether reproductively capable group members that are not providing care differ in androgen levels from those that are providing care. Given that most helpers do provide care to young, it may be necessary to hormonally manipulate helpers to get them not to help at all. Finally, another obvious hormone candidate to investigate with respect to parental care is prolactin. In a number of species, prolactin has been shown to play an important role in modulating care (birds: Gratto-Trevor et al. 1990; Ketterson and Nolan 1994; Lormee et al. 2000; mammals: Ziegler 2000; Schradin and Anzenberger 2003; Schradin and Pillay 2004; fish: Schütz and Barlow 1997). To date, no one has examined prolactin in relation to care vs allocare in fishes.

In summary, our study is the first to examine hormone levels in both sexes in a cichlid and a cooperative breeder. Currently, in the literature, there is a reasonable description and a diversity in patterns in androgen (testosterone) secretion in relation to paternal behavior across vertebrate species but, as yet, there is little known about androgens and female behavior and life history in free living animals. Further study and experiments are needed to test the suggestion that testosterone and sex steroids in general may play a role in the expression of parental care (especially defensive care) and allocare in both male and female fishes in general.

Acknowledgements This study was conducted with the permission of Dr. H. Phiri, Dr. Ngalada, and Dr. C. Kapasa of the Zambian Ministry of Agriculture, Food and Fisheries and the Government of Zambia. We are grateful to the staff of the Lake Tanganyika Research Unit for their great help and cooperation in this study, and want to particularly acknowledge D. Sinyinza and R. Shapolla for their field assistance. We thank Susan Marsh-Rollo, Kai Linstrom, and two anonymous referees for their helpful comments on the manuscript. This work conformed to guidelines of the Canadian Council on Animal care and the Animal Research and Ethics Board at McMaster University. This study was also supported with funding by the Natural Sciences and Engineering Research Council of Canada in the form of Discovery and Equipment grants to SB and GVDK and scholarships to JKD and JLF.

\section{References}

Asa CS, Seal US, Plotka ED, Letellier MA, Mech LD (1986) Effect of anosmia on reproduction in male and female wolves (Canis lupus). Behav Neurosci Biol 46:272-284

Balshine S, Leach B, Neat F, Reid H, Taborsky M, Werner N (2001) Correlates of group size in a cooperatively breeding cichlid fish (Neolamprologus pulcher). Behav Ecol Sociobiol 50:134-140

Balshine-Earn S, Neat FC, Reid H, Taborsky M (1998) Paying to stay or paying to breed? Field evidence for direct benefits of helping behaviour in a cooperatively breeding fish. Behav Ecol 9:432438

Bender N, Heg D, Hamilton IM, Bachar Z, Taborsky M, Oliveira RF (2006) The relationship between social status, behaviour, growth and steroids in male helpers and breeders of a cooperatively breeding cichlid. Horm Behav 50:173-182 
Bergmüller R, Heg D, Taborsky M (2005) Helpers in a cooperatively breeding cichlid stay and pay or disperse and breed, depending on ecological constraints. Proc R Soc B 272:325-331

Brouwer L, Heg D, Taborsky M (2005) Experimental evidence for helper effects in a cooperatively breeding cichlid. Behav Ecol 16:667-673

Buchner AS, Sloman KA, Balshine S (2004) They physiological effects of social status in the cooperatively breeding cichlid Neolamprologus pulcher. J Fish Biol 65:1080-1095

Carlson AA, Young AJ, Russel AF, Bennett NC, McNeilly AS, Clutton-Brock T (2004) Hormonal correlates of dominance in meerkats (Suricata suricatta). Horm Behav 46:141-150

Clark MM, Galef BG Jr (1999) Testosterone-mediated trade-off between parental and sexual effort in male Mongolian gerbils (Meriones unguicalatus). J Comp Psychol 113:388-395

Cockburn A (1998) Evolution of helping behaviour in cooperatively breeding birds. Ann Rev Ecolog Syst 29:141-177

Creel S (2001) Social dominance and stress hormones. Trends Ecol Evol 16:491-497

Creel S, Creel NM, Mills GLM, Montfort SL (1993) Behavioral and endocrine correlates of reproductive suppression in Serengeti dwarf mongooses. Anim Behav 43:231-245

Desjardins JK, Hazelden MR, Van der Kraak GJ, Balshine S (2006) Male and female cooperatively breeding fish provide support for the 'Challenge Hypothesis'. Behav Ecol 17:149-154

Desjardins JK, Fitzpatrick JL, Stiver KA, Milligan N, Van Der Kraak GJ, Balshine S (2007) Costs and benefits of polygyny in the cichlid, Neolamprologus pulcher. Anim Behav (in press)

Fitzpatrick JL, Desjardins JK, Stiver KA, Montgomerie R, Balshine S (2006) Male reproductive suppression in the cooperatively breeding fish Neolamprologus pulcher. Behav Ecol 17:25-33

Foerster K, Poesel A, Kunc H, Kempenaers B (2002) The natural plasma testosterone profile of male blue tits during the breeding season and its relation to song output. J Avian Biol 33:269-275

Gratto-Trevor CL, Fivizzani AJ, Oring LW, Cooke F (1990) Seasonal change in gonadal steroids of a monogamous versus a polyandrous shorebird. Auk 107:718-729

Goymann W, Moore IT, Scheuerlein A, Hirschenhauser K, Grafen A, Wingfield JC (2004) Testosterone in tropical birds: effects of environment and social factors. Am Nat 164:327-334

Hau M (2007) Regulation of male traits by testosterone: implications for the evolution of vertebrate life histories. Bioessays 29:138144

Hegner R, Wingfield JC (1987) Effects of experimental manipulation of testosterone levels on parental investment and breeding success in male house sparrows. Auk 104:462-469

Hirschenhauser K, Winkler H, Oliveira RF (2003) Comparative analysis of male androgen responsiveness to social environment in birds: the effects of mating systems and paternal incubation. Horm Behav 43:508-519

Ketterson ED, Nolan Jr V (1994) Male parental behavior in birds. Ann Rev Ecolog Syst 25:601-628

Ketterson ED, Nolan V Jr, Cawthorn MJ, Parker PG, Ziegenfus C (1996) Phenotypic engineering: using hormones to explore the mechanistic and functional bases of phenotypic variation in nature. Ibis 138:70-86

Ketterson ED, Nolan V Jr, Sandell M (2005) Testosterone in females: mediator of adaptive traits, constraint on sexual dimorphism, or both? Am Nat 166:85-98

Khan MZ, McNabb FMA, Walters JR, Sharp PJ (2001) Patterns of testosterone and prolactin concentrations and reproductive behaviour of helpers and breeders in the cooperatively breeding redcockaded woodpecker (Picoides borealis). Horm Behav 40:1-13

Knapp R, Wingfield JC, Bass AH (1999) Steroid hormones and paternal care in the plainfin midshipman fish (Porichthys notatus). Horm Behav 35:81-89
Lindeque M, Skinner JD (1982) Fetal androgens and sexual mimicry in spotted hyenas (Crocuta crocuta). J Reprod Fertil 65:405-410

Lormee H, Jouventin P, Lacroix A, Lallemand J, Chastel O (2000) Reproductive endocrinology of tropical seabirds: sex-specific patterns in LH, steroids, and prolactin secretion in relation to parental care. Gen Comp Endocrinol 117:413-426

Lynn SE, Hayward LS, Benowitz-Fredericks ZM, Wingfield JC (2002) Behavioural insensitivity to supplementary testosterone during the parental phase in the chestnut-collared longspur, Calcarius ornatus. Anim Behav 63:795-803

Lynn SE, Walker BG, Wingfield JC (2005) A phylogenetically controlled test of hypotheses for behavioral insensitivity to testosterone in birds. Horm Behav 47:170-177

Magee SE, Neff BD, Knapp R (2006) Plasma levels of androgens and cortisol in relation to breeding behaviour in parental male bluegill sunfish, Lepomis macrochirus. Horm Behav 49:598-609

Mays NA, Vleck CM, Dawson J (1991) Plasma luteinizing hormone, steroid hormones, behavioral role and nest stage in cooperatively breeding Harris' Hawks (Parabuteo unicinctus). Auk 108:619637

McMaster ME, Munkittrick KR, Jardine JJ, Robinson RD, Van Der Kraak GJ (1995) Protocol for measuring in vitro steroid production by fish gonadal tissue. Can Tech Rep Fish Aquat Sci., Burlington, Ontario: Fisheries and Oceans Canada

Møller AP, Garamszegi LZ, Gil D, Hurtrez-Bousses S, Eens M (2005) Correlated evolution of male and female testosterone profiles in birds and its consequences. Behav Ecol Sociobiol 58: $534-544$

Nelson RJ (2000) An introduction to behavioral endocrinology, 2nd edn. Sinauer Associates, MA

Oliveira RF (2006) Neuroendocrine mechanisms of alternative reproductive tactics in fish. In: Sloman KA, Wilson RD, Balshine $\mathrm{S}$ (eds) Behaviour and physiology of fish. Elsevier Academic Press Publication, San Diego, California, pp 297-358

Oliveira RF, Hirschenhauser K, Canario AVM, Taborsky M (2003) Androgen levels of reproductive competitors in a cooperatively breeding cichlid. J Fish Biol 63:1615-1620

Oring L, Fivizzani A, el Halawani ME (1989) Testosterone induced inhibition of incubation in the spotted sandpiper (Actitus mecularia). Horm Behav 23:412-423

Páll MK, Mayer I, Borg B (2002) Androgen and behavior in the male three-spined stickleback, Gasterosteus aculeatus I.-Changes in 11-ketotestosterone levels during the nesting cycle. Horm Behav 41:377-383

Peters A (2002) Testosterone and the trade-off between mating and paternal effort in extrapair-mating superb fairy-wrens. Anim Behav 64:103-112

Peters A, Astheimer LB, Cockburn A (2001) The annual testosterone profile in cooperatively breeding superb fairy wrens, Malurus cyaneus, reflects their extreme infidelity. Behav Ecol Sociobiol 50:519-527

Poiani A, Fletcher T (1994) Plasma levels of androgens and gonadal development of breeders and helpers in the bell miner (Manorina melanophrys). Behav Ecol Sociobiol 34:31-41

Rodgers EW, Earley RL, Grober MS (2006) Elevated 11-ketotestosterone during paternal behavior in the blubanded goby (Lythrypnus dalli). Horm Behav 49:610-614

Ros AFH, Bruintjes R, Santos RS, Canario AVM, Oliveira RF (2004) The role of androgens in the trade-off between territorial and parental behavior in the Azorean rock-pool blenny, Parablennius parvicornis. Horm Behav 46:491-497

Saino N, Møller AP (1995) Testosterone-induced depression of male parental behavior in the barn swallow: female compensation and effects of seasonal fitness. Behav Ecol Sociobiol 35:151-157

Schoech SJ, Mumme RL, Moore MC (1991) Reproductive endocrinology and mechanisms of breeding inhibition in cooperatively 
breeding Florida scrub-jays (Aphelocoma c. coerulescens). Condor 93:354-364

Schoech SJ, Mumme RL, Wingfield JC (1996) Prolactin and helping behaviour in the cooperatively breeding Florida scrub-jay Aphelocoma c. coerulescens. Anim Behav 52:445-456

Schoech SJ, Reynolds SJ, Boughton RK (2004) Endocrinology. In: Koenig WD, Haydock J (eds) Ecology and evolution of cooperative breeding in birds. Cambridge University Press, Cambridge, UK, pp 128-141

Schradin C, Anzenberger G (2003) Prolactin levels in paternal striped mouse (Rhabdomys pumilio) fathers. Physiol Behav 81:43-50

Schradin C, Pillay N (2004) Development of prolactin levels in marmoset males: from adult son to first-time father. Horm Behav 46:670-677

Schütz M, Barlow GW (1997) Young of the midas cichlid get biologically active non-nutrients by eating mucus from the surface of their parents. Fish Physiol Biochem 16:11-18

Sikkel PC (1993) Changes in plasma androgen levels associated with changes in male reproductive behavior in a brood cycling marine fish. Gen Comp Endocrinol 89:229-237

Solomon WD, French JA (1997) The study of mammalian cooperative breeding. In: Solomon WD, French JA (eds) Cooperative breeding in mammals. Cambridge University Press, Cambridge, UK, pp 1-10

Staub NL, De Beer M (1997) The role of androgens in female vertebrates. Gen Comp Endocrinol 108:1-24

Stiver KA, Dierkes P, Taborsky M, Balshine S (2004) Dispersal patterns and status changes in a cooperatively breeding cichlid, Neolamprologus pulcher: evidence from microsatellite analyses and behavioural observations. J Fish Biol 65:91-105

Stiver KA, Dierkes P, Taborsky M, Gibbs HL, Balshine S (2005) Relatedness and helping in fish: examining the theoretical predictions. Proc R Soc B 272:1593-1599
Stiver KA, Fitzpatrick JL, Desjardins JK, Balshine S (2006) Sex differences in rates of territory joining and inheritance in a cooperatively breeding cichlid fish. Anim Behav 71:449-456

Taborsky M (1984) Broodcare helpers in the cichlid fish, Lamprologus brichardi: their costs and benefits. Anim Behav 32:1236-1252

Taborsky M (1985) Breeder-helper conflict in a cichlid fish with broodcare helpers: an experimental analysis. Behaviour 95:45-75

Van Duyse E, Pinxten R, Eens M (2000) Does testosterone affect the trade-off between investment in sexual/territorial behaviour and parental care in male great tits? Behaviour 137:1503-1515

Vleck CM, Brown JL (1999) Testosterone and social reproductive behaviour in Aphelocoma jays. Anim Behav 58:943-951

Werner NY, Balshine S, Leach B, Lotem A (2003) Helping opportunities and space segregation in cooperatively breeding cichlids. Behav Ecol 14:749-756

Wingfield JC, Hegner RE, Dufty AM Jr, Ball GF (1990) The "Challenge Hypothesis": theoretical implications for patterns of testosterone secretion, mating systems and breeding strategies. Am Nat 136:829-846

Wingfield JC, Hegner RE, Lewis D (1991) Circulating levels of luteinizing hormone and steroid hormones in relation to social status in the cooperatively breeding white browed sparrow weaver, Plocepasse mahali. J Zool 225:43-58

Young AJ, Carlson AA, Monfort SL, Russell AF, Bennett NC, Clutton-Brock T (2005) Stress and suppression of subordinate reproduction in cooperatively breeding meerkats. Proc Nat Acad Sci USA 103:12005-12010

Ziegler TE (2000) Hormones associated with non-maternal infant care: a review of mammalian and avian studies. Folia Primatol 1:6-21

Zysling DA, Greives TJ, Breuner CW, Casto JM, Demas GE, Ketterson ED (2006) Behavioral and physiological responses to experimentally elevated testosterone in female dark-eyed juncos (Junco hyemalis carolinensis). Horm Behav 50:200-207 